\title{
Diabetic Mastopathy: A Case Report and Literature Review
}

\author{
G. Neetu ${ }^{a}$ R. Pathmanathan ${ }^{\mathrm{a}}$ Ngun Kok Weng ${ }^{\mathrm{b}}$ \\ aDepartment of Pathology, Monash University Sunway Campus, Bandar Sunway, \\ Selangor, 'Department of Surgery, Kuantan Specialist Hospital, Kuantan, Pahang, \\ Malaysia
}

\section{Key Words}

Diabetic mastopathy · Insulin-dependent · Breast cancer · Pseudomalignancy

\begin{abstract}
Diabetic mastopathy is a rare fibroinflammatory breast disease characterized by lymphocytic lobulitis, ductitis, and perivasculitis with stromal fibrosis. This lesion often presents as a discretely palpable uni- or bilateral mass in long-standing type I diabetes and other autoimmune diseases. We report a case of insulin-dependent diabetic mastopathy, which presented clinically as an indeterminate breast lump suspicious for malignancy. The patient is a 36-year-old woman who had type 1 insulin-dependent diabetes mellitus. Mammography and ultrasonography raised a suspicion of malignancy, and an excisional biopsy was performed. A previous biopsy had shown no evidence of malignancy. Histopathological examination now showed dense keloid-like stromal fibrosis with epithelioid-like and spindly myofibroblasts and a characteristic lymphocytic infiltration around blood vessels in and around lobules and ducts, features consistent with diabetic mastopathy. The literature is briefly reviewed.
\end{abstract}

\section{Introduction}

Diabetic mastopathy (DMP) is a collection of clinical, radiological and histological features found in dense fibrous masses of the breast initially described by Soler and Khardori [1]. The disease is associated with long-standing type 1 insulin-dependent diabetes mellitus (IDDM) but has been reported in other autoimmune disorders. These patients present with a palpable hard, painless, irregular mass solitarily in one breast or bilateral breasts. The clinical and imaging findings are inconclusive, and these lesions are often misdiagnosed as breast carcinomas. The recognition of this rare but benign disease is crucial to avoid surgical biopsies which are more than necessary. 


\begin{tabular}{|c|c|c|c|}
\hline $\begin{array}{l}\text { Cose Reports in } \\
\text { Oncaloy }\end{array}$ & $\begin{array}{l}\text { Case Rep Oncol 2010;3:245-251 } \\
\text { D0I: } 10.1159 / 000318641\end{array}$ & Published online: July 16, 2010 & $\begin{array}{l}\text { (c) } 2010 \text { S. Karger AG, Basel } \\
\text { ISSN } 1662-6575 \\
\text { www.karger.com/cro }\end{array}$ \\
\hline
\end{tabular}

\section{Case Presentation}

The patient described is a 36-year-old Chinese female, who presented with a lump in her left breast of 2 months' duration. There was no associated pain, but she noticed an increasing discomfort in the lump during menstruation. She had been treated for type I diabetes for the last 7 years and had a secondary complication of diabetic retinopathy for which a photocoagulation therapy and vitrectomy was performed. She also had a history of autoimmune diseases, namely rheumatoid arthritis for the past 12 years and thyrotoxicosis for the past 4 years, and was on steroid and antithyroid medication for both diseases, respectively. Investigations for autoimmune antibodies were not done on this patient. There was a family history of diabetes and arthritis.

The examination showed a hard, relatively immobile, painless mass whose borders appeared to merge into the normal surrounding breast tissue. The mass was situated in the areolar region of the upper outer quadrant of the left breast, measuring approximately $5 \mathrm{~cm}$. Axillary lymph nodes were absent and there was no history of nipple discharge. The right breast examination was unremarkable.

Mammography revealed increased fibrofatty densities in both breasts with a subareolar nodular dense mass in the left breast. There were no microcalcifications detected. A poorly defined hypoechoeic mass at 11-12 o'clock position in the subareolar region of left breast was demonstrated on ultrasonogram. Breast imaging reporting and data system (BIRADS) categorization was an indeterminate breast lump, and hence the clinical impression was suspicion of breast carcinoma. A core needle biopsy followed by an excision biopsy was performed. The needle biopsy revealed stromal fibrosis on histopathology without the other constellating features. Gross pathology of the excision specimen demonstrated a whitish irregular firm fibrotic mass measuring $7 \times 6 \times 4 \mathrm{~cm}$ (fig. 1). There was no visible mass lesion in the specimen. Histologically, the lesion showed a striking lymphocytic lobulitis and ductitis (fig. 2) comprising small mature lymphocytes, a keloid-like stromal expansion (fig. 3) with increased stromal spindle cells, occasional epithelioid-like myofibroblasts and a prominent lymphocytic vasculitis (fig. 4). Plasma cells were rare and there were no germinal centers observed. The case met all the histologic parameters fitting the diagnosis of DMP.

The patient currently remains well and is on follow-up.

\section{Discussion}

DMP is a rare entity of self-limiting fibroinflammatory disease of the breast associated with type 1 diabetes mellitus occurring in premenopausal women.

Soler and Khardori [1] first described this disease in 1984 in patients with type 1 IDDM. Most of the patients were women under 30 years of age with complications arising from diabetes such as retinopathy, neuropathy and nephropathy. The combination of stromal fibrosis and lymphocytic vasculitis in these patients was subsequently described as mastopathy in insulin-dependent diabetics by Byrd et al. [2].

Tomaszewski et al. [3] found that certain microscopic features like epithelioid cells in the fibrous stroma were specific for IDDM. The histopathologic criteria were further defined by Seidman et al. [4] who proposed a combination of histologic features to confirm diabetic mastopathy. These were a collagenous stroma with keloid-like features with a slightly increased concentration of stromal spindle cells and mature lymphocytes clustered circumferentially around small blood vessels as well as in and around lobules and ducts. They reported a mean duration of greater than 13 years (range 4-27 years) for DMP to develop. The disease was not limited to women but was exceptionally seen in men.

In 1989, Logan et al. [5] mentioned criteria for the radiographical diagnosis of DMP, i.e. a long-term history of IDDM, hard palpable masses, mammographic dense glandular tissue and strong ultrasound acoustic shadowing. Nevertheless, these radiologic findings can still be mistaken for a malignancy. They advocated the use of fine needle aspiration cytology (FNAC) in the diagnosis of DMP. They mentioned the firm resistance 
experienced during the back-and-forth motion of the needle, which was stronger than in the other breast, as a clue to the diagnosis of DMP. Unfortunately, DMP contains little cellular material, making cytological diagnosis difficult. This necessitates either core needle biopsy or excision biopsy for the first diagnosis.

DMP has also been described in type II diabetes mellitus, though with a lower incidence compared with type I diabetes mellitus. Some researchers reported similar features in autoimmune diseases, like thyroiditis and systemic lupus erythematosus, where they described the condition as lymphocytic mastopathy [6]. In the present case report, our patient had type 1 diabetes mellitus, arthritis and thyrotoxicosis.

Even though many reports have been published on DMP in radiology, pathology and surgical literature, this clinical condition is poorly recognized since breast examination is not routinely performed in young diabetic patients. DMP may be confused with breast carcinoma [7] because of the difficulty to distinguish between these two entities both physically and by imaging. In cases with an appropriate clinical history and high index of suspicion, an ultrasound-guided core biopsy was found to be useful for the primary diagnosis of DMP [8].

The pathogenesis of DMP is not completely understood, but many theories have been proposed considering a multifactorial etiology. Sternberg et al. [9] in their studies found that the glycosylation and increased intermolecular cross linkages in diabetics render collagen resistant to degradation. This leads to the accumulation of connective tissue characteristic of some connective tissue disorders in diabetics, including mastopathy. Tomaszewski [3] hypothesized that advanced glycosylated end products formed in hyperglycemia act as neo-antigen and trigger an autoimmune response with B-cell proliferation and autoantibody production. The resultant cytokine release would lead to matrix expansion.

Lymphocytic mastitis in DMP is associated with B cell lymphocytes and nondiabetic mastitis shows a higher proportion of T cells [3]. In a study of the association of B cell lymphocytosis with marginal lymphoma, no risk of progression to malignant lymphoma was found [10]. DMP being a benign condition, immunohistochemistry of the lymphoid cells was omitted in our patient.

Hunfeld and Bassler [11], who compared the stromal and lymphocytic features of DMP and non-diabetic lymphocytic mastitis, found that the latter has higher proportions of T cells and less pronounced fibrosis. DMP can be differentiated by the greater stromal fibrosis, lobular atrophy and the presence of epithelioid myofibroblasts. Our case showed similar epithelioid myofibroblasts in the stroma.

Some researchers who studied the prognosis of DMP found that these lesions are prone to single or multiple recurrence in the same breast or the contralateral breast [12]. Camuto [13] reported that $60 \%$ of DMP recur after surgical excision and tend to be in the same location, involving more breast tissue than the preceding lesion; therefore, surgical biopsy should not be considered.

Ely et al. [14] studied 19 patients who were followed up for 14 years and found that the recurrence rate was a substantial $32 \%$. The authors questioned the specificity of the diagnostic criteria for DMP as these lesions were also found in type 2 diabetes and nondiabetic patients.

Long-standing IDDM in young women hence warrants a routine clinical examination of the breast. The recurrence can be managed conservatively in documented cases. Core 
needle biopsy under ultrasound guidance eliminates redundant surgical procedures that may exacerbate the condition. This necessitates follow-up in such patients.

It is important for the pathologists not to misdiagnose DMP as it can recur. The lesion can also simulate breast carcinoma, hence such patients may be spared from many unwarranted surgical biopsies if the radiologists and pathologists are aware of this rare breast disease. There is no evidence to suggest that DMP predisposes to the development of breast carcinoma or stromal neoplastic diseases.

FNAC can be used to monitor patients with recurrent lesions in a proven case of DMP, as it can show ductal epithelial cells in clusters, lymphocytes and epithelioid fibroblasts, which are readily identified in connective tissue fragments [15].

\section{Conclusion}

Recognizing DMP requires an awareness of the existence of this entity and a careful correlation of the patient's clinical history with the physical, radiological and pathological examinations. As the disease can be managed conservatively but may recur, an accurate diagnosis is essential to avoid unwanted multiple surgical biopsies. Monitoring of the patients by FNAC would be sufficient once the pathologic diagnosis is confirmed.

\section{Consent}

Written informed consent was obtained from the patient for publication of this case report and accompanying images. A copy of the written consent is available for review by the Editor-in-Chief of this journal.

\section{Acknowledgements}

The authors would like to thank the staff in the histopathology laboratory of Sime Darby Medical Centre for providing technical help and general support. 


\begin{tabular}{c|l|l|l}
$\begin{array}{c}\text { Case Reports in } \\
\text { Oncolady }\end{array}$ & $\begin{array}{l}\text { Case Rep Oncol 2010;3:245-251 } \\
\text { D0I: 10.1159/000318641 }\end{array}$ & Published online: July 16, 2010 & $\begin{array}{l}\text { O 2010 S. Karger AG, Basel } \\
\text { ISSN 1662-6575 } \\
\text { www.karger.com/cro }\end{array}$ \\
\hline
\end{tabular}

Fig. 1. Gross specimen sectioned to reveal dense whitish fibrous stroma in diabetic mastopathy.

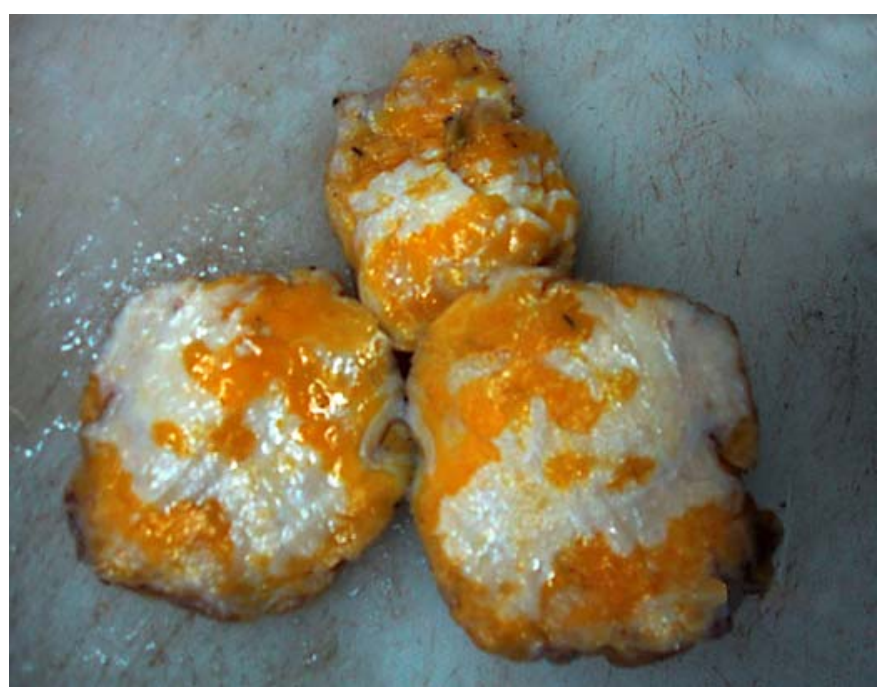

Fig. 2. Histopathology showing lymphocytic ductitis on HE stain.

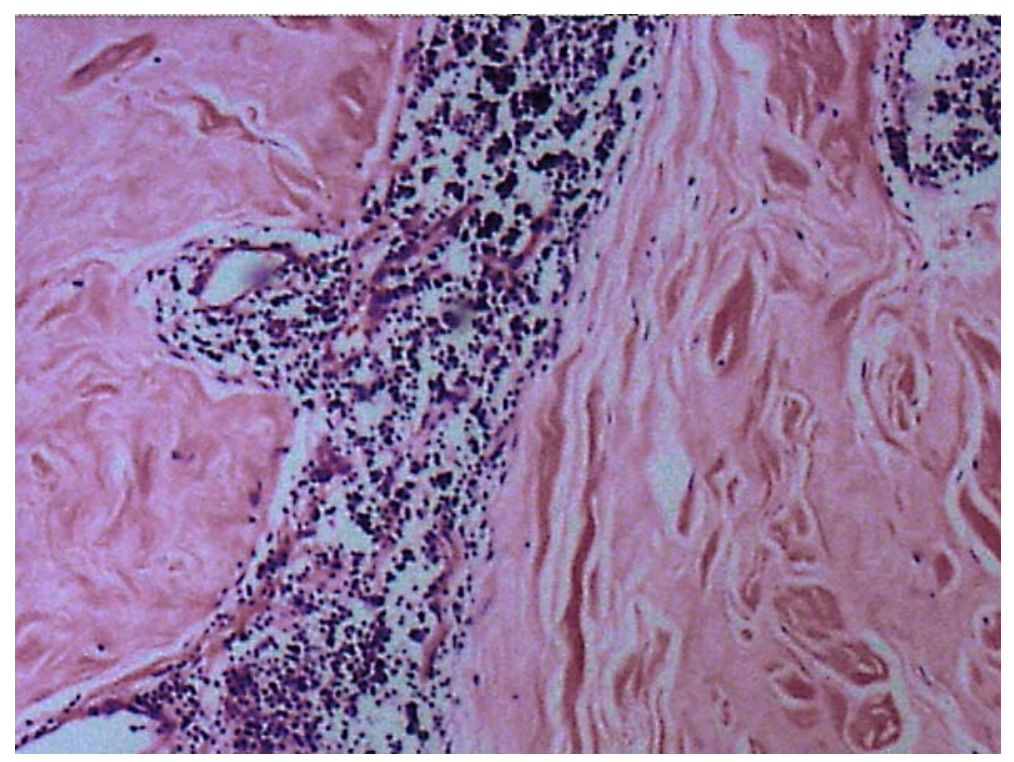




\begin{tabular}{c|l|l|l}
$\begin{array}{c}\text { Case Reports in } \\
\text { Oncolady }\end{array}$ & $\begin{array}{l}\text { Case Rep Oncol 2010;3:245-251 } \\
\text { D0I: 10.1159/000318641 }\end{array}$ & Published online: July 16, 2010 & $\begin{array}{l}\text { O 2010 S. Karger AG, Basel } \\
\text { ISSN 1662-6575 } \\
\text { www.karger.com/cro }\end{array}$ \\
\hline
\end{tabular}

Fig. 3. Histopathology showing keloid-like stromal fibrosis with scattered myofibroblasts.

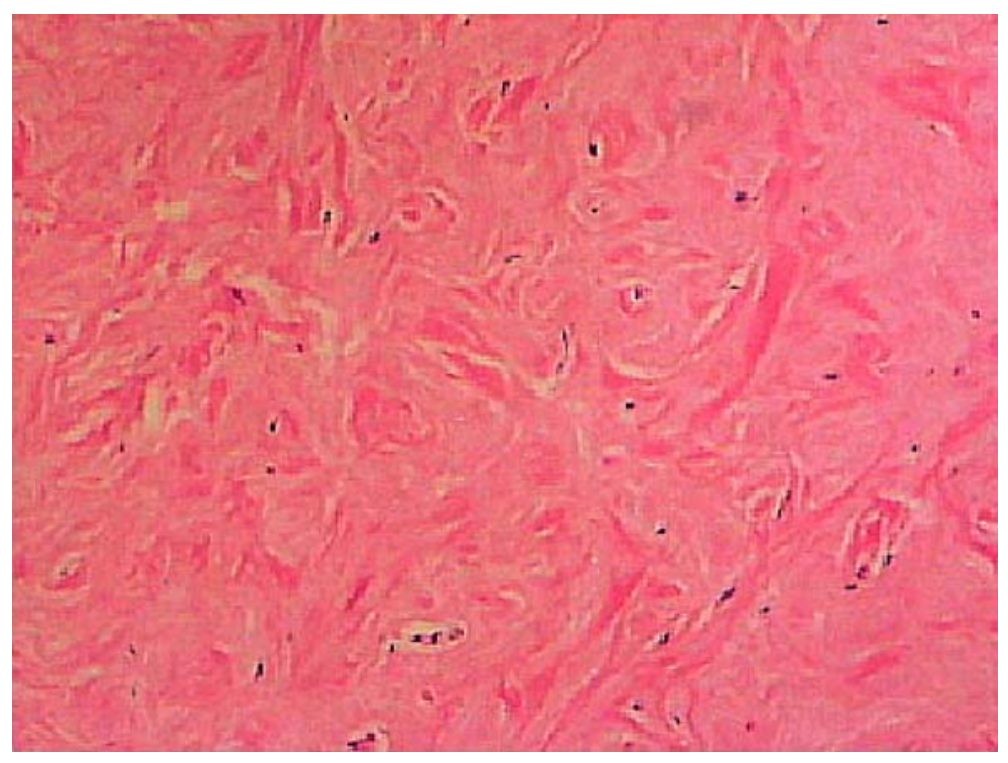

Fig. 4. Histopathology showing perivascular lymphocytic infiltration.

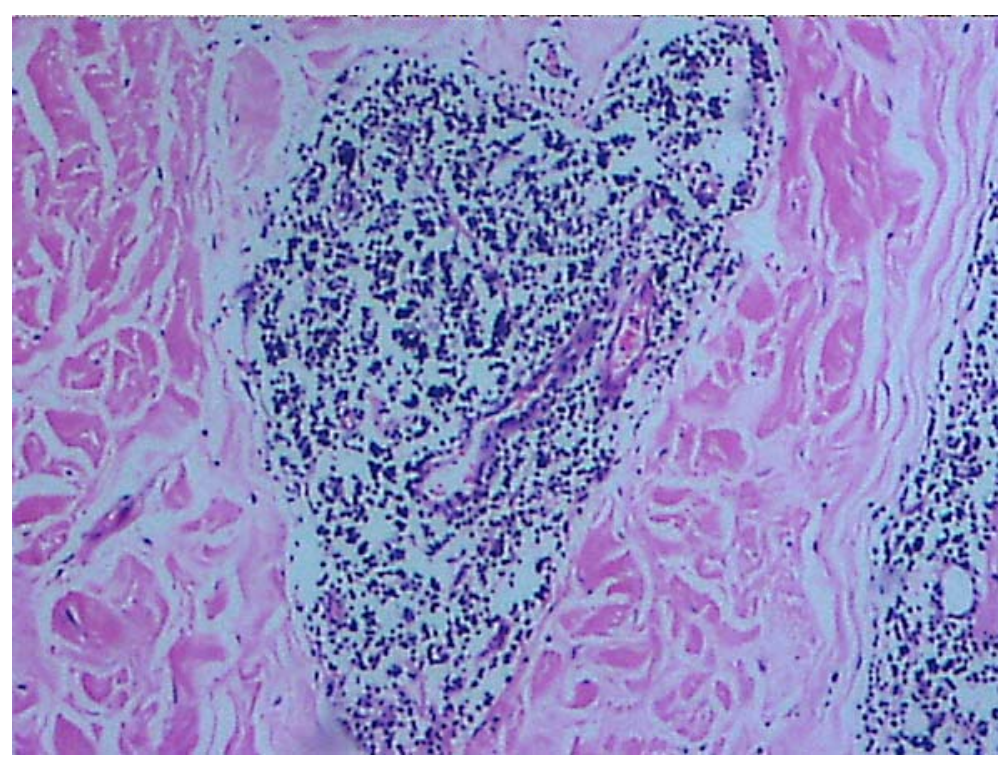




\section{References}

1 Soler NG, Khardori R: Fibrous disease of the breast, thyroiditis, and cheiroarthropathy in type I diabetes mellitus. Lancet 1984;1:193-195.

2 Byrd BF, Hartman WH, Graham LS, et al: Mastopathy in insulin-dependent diabetics. Ann Surg 1987;205:529-532.

-3 Tomaszewski JE, Brooks JS, Hick D, Livolsi VA: Diabetic mastopathy: a distinctive clinicopathological entity. Hum Pathol 1992;23:780-786.

4 Seidman JD, Schnaper LA, Phillips LE: Mastopathy in insulin requiring diabetes mellitus. Hum Pathol 1994;25:819-824.

5 Logan WW, Hoffman NY: Diabetic fibrous breast disease. Radiology 1989;172:667-670.

6 Schwartz IS, Strauchen JA: Lymphocytic mastopathy: an autoimmune disease of the breast? Am J Clin Pathol 1990;93:725-730.

7 Ashton MA, Lefkowitz M, Tavassoli FA: Epithelioid stromal cells in lymphocytic mastitis - a source of confusion with invasive carcinoma. Mod Pathol 1994;7:4954.

$>8$ Andrews-Tang D, Diamond AB, Rogers L, et al: Diabetic mastopathy: adjunctive use of ultrasound and utility of core biopsy in diagnosis. Breast J 2006;6:183-188.

9 Sternberg M, Cohen-Fortere L, Peyroux J: Connective tissue in diabetes mellitus: biochemical alterations of the extracellular matrix with special reference to proteoglycans, collagens and basement membranes. Diabetes Metab 1985;11:2750.

10 Riccardo V, John T, Richard VF, Bertram S, Celina GK: Lymphocytic mastitis and diabetic mastopathy: a molecular, immunophenotypic and clinicopathologic evaluation of 11 cases. Mod Pathol 2003;16:223-228.

11 Hunfeld KP, Bassler R: Lymphocytic mastitis and fibrosis of the breast in long standing insulin-dependant diabetics. Gen Diagn Pathol 1997;143:49-58.

12 Bayer U, Horn LC, Schultz HG: Bilateral, tumorlike diabetic mastopathy: progression and regression of the disease during 5-year follow-up. Eur J Radiol $1998 ; 26: 248-253$.

13 Camuto PM, Zetrenne E, Ponn T: Diabetic mastopathy: a report of 5 cases and a review of literature. Arch Surg 2000;135:1190-1193.

14 Ely KA, Tse G, Simpson JF, Clarfeld R, Page DL: Diabetic mastopathy: a clinicopathologic review. Am J Clin Pathol 2000;113:541-545.

15 Rollins SD: Fine-needle aspiration cytology of diabetic fibrous mastopathy. Diagn Cytopathol 1993;9:687-690. 